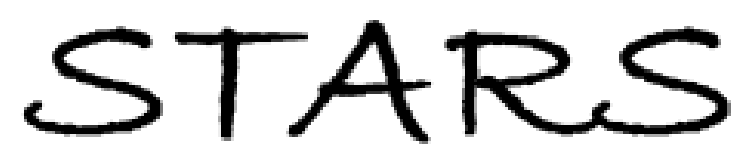

University of Central Florida

STARS

$11-1-2014$

\title{
Intercultural Interactions Outside the Classroom: Narratives on a U.S. Campus
}

Xinran Lehto

Liping A. Cai

Xiaoxiao Fu

University of Central Florida, xiaoxiao.fu@ucf.edu

Yi Chen

Part of the Hospitality Administration and Management Commons, and the Tourism and Travel Commons

Find similar works at: https://stars.library.ucf.edu/rosenscholar

University of Central Florida Libraries http://library.ucf.edu

This Paper is brought to you for free and open access by the Rosen College of Hospitality Management at STARS. It has been accepted for inclusion in Rosen Faculty Scholarship and Creative Works by an authorized administrator of STARS. For more information, please contact STARS@ucf.edu.

\section{Original Citation}

Lehto, X.Y., Cai, L.A., Fu, X., \& Chen, Y. (2014). Intercultural interactions outside the classroom: Narratives on a U.S. campus. Journal of College Student Development, 55(8), 837-853.

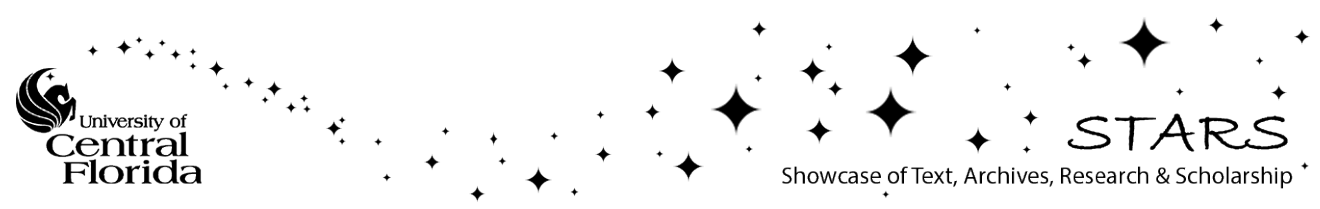




\section{PROJECT MUSE}

\section{Intercultural Interactions Outside the Classroom: Narratives}

on a US Campus

Xinran Y. Lehto, Liping A. Cai, Xiaoxiao Fu, Yi Chen

Journal of College Student Development, Volume 55, Number 8, November 2014, pp. 837-853 (Article)

Published by Johns Hopkins University Press

DOI: 10.1353/csd.2014.0083

$\Rightarrow$ For additional information about this article http://muse.jhu.edu/journals/csd/summary/v055/55.8.lehto.html 


\title{
Intercultural Interactions Outside the Classroom: Narratives on a US Campus
}

\author{
Xinran Y. Lehto Liping A. Cai Xiaoxiao Fu Yi Chen
}

This study provides a picture of the interactional experiences between domestic and international undergraduate students outside the classroom on a US campus. Based on 9 focus group sessions, 8 distinctive themes emerged as a result. The study revealed some similarities but many differences between domestic and international students, illuminating the lack of and barriers to intercultural learning. The findings highlight the challenges and opportunities currently faced on US campuses, thereby making a timely contribution to efforts at developing students' readiness to be successful in a global and multicultural environment.

It is becoming critically urgent for universities in the United States to develop future leaders and workers with global and multicultural competencies, as the nation is embracing an increasingly diverse society of its own and faces a more integrated yet complex global environment. A shift toward internationalizing undergraduate curricula and broader interdisciplinary training is necessary, but this is only the first step. Instilling intercultural skills and cultivating the ability to live and work in a transnational environment requires approaches that go beyond the structured, traditional classroom-learning environment. Such efforts need to permeate all aspects of today's undergraduate educational experience. Study abroad, for instance, has long been advocated as an effective means of intercultural competence development. However, this represents and benefits only a small percentage of college students in the United States. As such, the importance of international students to an institution's internationalization efforts cannot be overemphasized (Deardorff, 2006).

Students from other countries are de facto "imported" resources locally available for developing multicultural competencies. Opportunities have recently been increasing for universities to tap into such resources thanks to a rapid rise in international undergraduate enrollments, particularly from emerging economies such as China. The number of international students at colleges and universities in the United States reached a record high of 723,277 during the 2010/11 academic year, an increase of 5\% from the previous academic year (Institute of International Education, 2011). The top three countries of origin for international students are China, India and South Korea, together accounting for nearly half (46\%)

Xinran Y. Lehto is Professor of Hospitality and Tourism Management at Purdue University. Liping A. Cai is Professor and Associate Dean of the College of Health and Human Sciences at Purdue University. Xiaoxiao Fu is Assistant Professor of Hospitality Management at the University of Central Florida. Yi Chen is a doctoral graduate of Hospitality and Tourism Management from Purdue University. 
of international enrollments. The increasing number of international students brings greater diversity to the student body that can enrich the educational experiences of all and at the same time contribute to the cultivation of a global mindset and intercultural competencies. The potential can be realized when students interact and learn from each other both academically and culturally, both inside and outside classrooms. However, such interactions between international students and their American peers do not always take place. On the contrary, the interactions may become less frequent as the number of international students from a particular country increases so significantly that they begin to develop a critical mass and form their own communities.

It is not well understood how and how much students of different national backgrounds interact with each other. Even less is known about whether such contact and interaction, if significantly present on campus, brings positive outcomes in the multicultural development and overall college experience of both domestic and international students. The existing yet limited literature on intercultural contact in higher education is largely concerned with psychological adaptation and adjustment on the part of international students, and often its context is outside the United States (e.g., Barron \& Dasli, 2010). Although there have been attempts to understand how American students interact with international students and scholars in stimulating learning in the classroom (Barron \& Dasli, 2010; Deardorff, 2006), very little is known about their interactions outside the structured classroom-learning environment. Given that a significant part of undergraduate experience comes from activities outside the classroom, it is important to understand how these activities influence the quality of intercultural contact and interactions.

The current research is directed toward developing a better understanding of the intercultural exchange dynamics on US campuses. It contains four specific research questions:

1. How are domestic and international undergraduate students connected or disconnected outside their structured classroom-learning environment?

2. What are the existing and potential mechanisms for intercultural interactions?

3. To what extent do the existing institutional structure and composition of social connections facilitate the access to a wider range of opportunities for intercultural interactions?

4. How do students perceive the quality of intercultural interactions and the impact of such interactions on their campus life satisfaction and well-being?

\section{LITERATURE REVIEW}

Contact theory posits that intergroup contact can potentially improve intergroup attitude, perception, and behavior in terms of basic processes such as the "mere exposure" effect (Allport, 1954; Zajonc, 1968). Yet, contact per se is insufficient to enhance intergroup relations, and specific features of the contact may determine the social and psychological outcomes of intergroup contact (Pettigrew, 2008). Abundant literature describes how and under what situational circumstances intercultural contact can lead to positive outcomes. The linkage between intergroup contact and outcome variables such as reduction of prejudice and increase in intercultural appreciation are well established in applied social psychology (Brown \& Hewstone, 2005). However, only sporadic work has addressed whether and how nonacademic activities outside the classroom influence the quality of intercultural contact on US campuses. 


\section{Intercultural Dynamics on University Campuses}

With the increasing presence of international students on US campuses, the accompanying intercultural dynamics has caught researchers' attention. Prior studies have suggested that intercultural interactions between international and domestic students help the former improve and better adjust to their life in the United States (Trice, 2004; Zimmerman, 1995). Such improvements may be demonstrated in multiple ways, including improved language ability, communication effectiveness, cultural adaptation, social integration, and overall satisfaction with campus life. Zimmerman (1995) found international students' perception of their adjustment and their overall satisfaction with campus life were highly correlated with the extent to which they talked and interacted with domestic students. In a survey of 497 international students on a US campus, Trice (2004) noted that those who socialized with domestic students the most tended to socialize more with students from a variety of nationalities, participate actively in cultural events held on campus, and in general feel more comfortable with American culture.

Although the positive effect of intercultural dynamics has been widely acknowledged, especially for international students, emerging issues and challenges have also been noted in more recent investigations. A qualitative study of 114 international students conducted by Sherry, Thomas, and Chui (2010) found that $50 \%$ indicated they make friends merely with other international students and only $35 \%$ said that they had been successful in making American friends. The authors identified international students as a vulnerable population who had difficulties in adapting and adjusting to a new environment. In another study, a welcoming and receptive university environment and local community was believed to play an important role in the mental health of international students (Sumer, Poyrazli, \& Grahame, 2008). Pavel's study (2006) offers evidence that, in spite of the perceived importance and value of intercultural interactions, students still tend to form friendships with others sharing similar backgrounds.

In addition, researchers (e.g., Turner, 2006) have specifically examined contemporary classroom dynamics and suggested that domestic and international students tend not to interact readily and are likely to go through their program in parallel. Russell (2005) found that international students considered their U.K. counterparts to be cold, uncaring, and closed to other cultures. Recent research has begun to notice the perceptual and behavioral discrepancies in intercultural interaction between international and domestic students. Based on a survey of 121 university students in the United Kingdom, Barron and Dasli (2010) noted that international students were likely to strive for acceptance, adaptation, and integration in the new culture, whereas domestic students tended to be defensive and developed ethnocentric attitudes toward international students.

\section{Personal and Social Factors Outside the Classroom}

Individual factors such as personality and value system play a role in one's choice of activities outside the classroom. Such activities can range from solitary activities, to in-group partners (e.g., friends and families), and to out-group, or ad hoc, companionship that may or may not entail contact and interaction with individuals from another culture. Many of these activities are leisure in nature. Brown and Hewstone (2005) proposed an integrative theory of intergroup contact that systematically examines factors influencing the quality and quantity of intergroup contact. Some of the key 
influential factors are personal in nature, such as intergroup attitude, intergroup anxiety, and personal value. Burch (2009) hypothesized that individuals may have competing tendencies (compensatory vs. familiarity) when it came to leisure choice. The compensatory hypothesis suggests that whenever an individual is given the opportunity to avoid his or her regular routine, he or she will seek a directly opposite activity. For example, an individual whose routine activity is sedentary will seek vigorous play. The familiarity hypothesis, on the other hand, assumes that an individual who has established a comfortable routine for social survival tends to favor security over the possible but uncertain rewards of the unfamiliar activity. Given the freedom of choice, the individual will seek familiar leisure activities, perhaps with individuals with a familiar social and/or cultural background.

There is also social involvement in activities of leisure orientation. Leisure can be defined by the universe of social relations it generates, by the nature of interactions, and by the identification of the preferred partners. The most evident function of the norms of interaction is to contribute to the integration of groups. Some social interactions are considered as best provided or facilitated by leisure contents and settings. Examples include family relations, friendship formation, and group identity development (e.g., Floyd, Shinew, McGuire, \& Noe, 1994). Although leisure is a form of interaction that allows one to choose one's partners contrary to some other forms of activities, this free choice of partners and relationships can be influenced by social contextual variables such as peer pressure, institutional/community or programmatic structural facilitation or hindrance, and group salience. Friendships, for example, can exert significant influence on young people's leisure activity choices through such mechanisms as friend selection, socialization of interest, and peer and in-group pressure (Brown \& Klute, 2006).

\section{METHODOLOGY}

Social constructivism was employed as the epistemological approach to orient the study. This approach holds that social reality is constructed through subjective meanings of experiences (Creswell, 2007). The construction of such meanings may vary across different individuals, requiring the researcher to "rely as much as possible on the participants' views of the situation" (2007, p. 20). Informed by the epistemology, the study adopts phenomenology as the guiding methodological framework to "describe the meaning of the lived experiences for several individuals about a concept or phenomenon" (Creswell, 1998, p. 51). The key informants are those who have had experiences in common, and the researcher's role is to listen to what participants say about their experience (Creswell, 2007). Such focus is best suited for our research problem to understand how students perceive, experience, and describe the intercultural encounters in leisure settings. Phenomenology has been widely used in studies of college students' experiences (e.g., Rockenbach, Walker, \& Luzader, 2012), contributing to common understandings for various stakeholders such as teachers, administrators, and policymakers.

A focus group technique was used "to explore individuals' opinions, attitudes, beliefs, values, discourses, and understandings of things" (Paul \& Lynne, 2001, p. 81). A focus group is preferred to other data collection methods because of its advantages: (a) it is suitable for eliciting participants' subjective interpretation of their experience (Carlsen \& Glenton, 2011), (b) the interactive atmosphere is conducive to the exchange of ideas and perspectives with other individuals who had similar experiences (Kelly, 2003), (c) it allows 
substantive data points to emerge in a relatively shorter time than individual interviews (Morgan, 1996), and (d) it is suitable for exploring college students' perceptions and experiences about certain services or programs (Kaase \& Harshbarger, 1993).

\section{Sample}

This study employed a purposive, convenience sampling approach. Domestic and international students on the campus of a major university in the midwestern United States were the target population. Recruitment venues included two undergraduate management classes and several international student organizations. The two undergraduate classes had cultural and demographic compositions fairly typical of the population of the university. A written invitation to participate in the study was circulated both in the classes and through the student associations. No compensation was offered, but pizza and drinks were provided at the sessions. A total of 59 undergraduate students with majors in management, engineering, natural science, and economics volunteered to participate. The initial intention was to have three types of focus groups: homogeneously domestic, homogeneously international, and a mix of domestic and international students. However, due to logistical limitations typified by students' schedules, the researchers were unable to accomplish the initial goal but did accommodate students' time preferences. As a result, all sessions comprised a mix of domestic and international participants.

\section{Data Collection and Analysis}

Before the focus groups were launched, a moderator's guide was created based on the research questions. The overall research question was to understand whether and how intercultural interactions occur outside the classroom, specifically in the leisure and social setting. A set of narrower semi-structured research questions was also developed to complement the overarching research question. These inquiries included general questions about students' leisure and social life, exchanges with domestic/international students in leisure scenarios, existing and potential leisure opportunities on and off campus, perceived need of intercultural exchange, and perception of such intercultural interaction in relation to campus life satisfaction and well-being.

Nine focus group sessions were conducted during October 4-27, 2011. Each session consisted of five to seven students and lasted approximately 90 minutes. A conference room free from distractions was provided for the participants to comfortably share their opinions. All sessions were moderated by the lead author, who is an experienced moderator, with the assistance of two additional researchers. Each session was carried out following the suggestions of Vaughn, Schumm, and Sinagub (1996). At the beginning, the moderator (a) welcomed and thanked students for their participation, (b) introduced study objectives, (c) emphasized anonymity and confidentiality in data handling, (d) clarified the role of moderator as a neutral facilitator, and (e) stressed the importance of speaking their mind and sharing experiences. Each participant was asked to make a selfintroduction, including first name, year at school, and whether he/she is a domestic or international. They were also asked to fill out a brief demographic survey, which gathered information on age, gender, nationality background, and leisure activities in which they frequently participated. With informed consent of participants, all sessions were recorded using both a video camera and a digital voice recorder for transcription purpose. Two assistant researchers also took observational notes, recording outstanding remarks and reactions. 
All digital files were transcribed by two assistant researchers independently. Guided by the methodological principles of phenomenology, the analysis followed the six phases of thematic analysis (Braun \& Clarke, 2006): (a) all researchers read the transcripts and researchers' field notes and became familiarized with the data; (b) researchers collectively discussed and reached a consensus about a list of words, phrases, or sentences that were frequently mentioned and elaborated by the participants; (c) after the initial list of codes was generated, researchers analyzed and sorted the codes into potential, overarching themes; (d) researchers reviewed and refined the identified themes for clarity and consistency (data under the same theme should present a consistent account, without too much overlap between themes); (e) the themes were defined and detailed stories were organized under each theme; and (f) researchers produced the final write-up report.

\section{RESULTS}

Of the 59 participants, 34 were domestic students and 25 were international students. Among the latter, 15 were from Mainland China, and the rest were from Taiwan, South Korea, Ireland, and Mexico. There were 20 males and 39 females. They reported frequent participation in group sports (e.g., soccer, football, volleyball, and bowling), working out (e.g., going to the gym and fitness classes), dining out (e.g., going to fast food outlets, ethnic restaurants, and bars), clubbing (e.g., student organizations and hobby-related clubs), travelling, partying, shopping, going to church, watching TV, playing musical instruments, visiting family, and online leisure activities. Most of the activities took place on or close to campus. Domestic students tended to spend more time on these activities than their international counterparts. Table 1 illustrates an initial attempt at categorization. The four categories include Leisure Activities, Social Network Establishment, Drivers for Intercultural Interactions Through Leisure, and Barriers to Intercultural Interactions Through Leisure.

The findings reveal some similarities but many differences between the domestic and international students in activities outside the classroom, how they form social networks, what drives them to seek interactions, their perceived barriers to such interactions, their perceptions of how such exchanges should occur, and what structural supports are needed to enable and sustain such interactions. Eight distinctive themes emerged from the analyses of coded responses, in conjunction with observational notes. The process of searching, reviewing, and refining the themes was based on data prevalence in terms of how frequently they were articulated by the participants and how in-depth and elaborately the participants discussed the issue.

\section{Theme 1: We See Them Everywhere but Don't Really Know Them}

The first theme that emerged is recognition of the significant number of international students. Most domestic students acknowledged the significant Asian presence (15.4\%) on campus. A common sentiment expressed by the domestic participants is that they are keenly aware of the cultural dynamic change, as most reported that they have had encounters with international students in the classroom and in project groups and have seen "them in groups everywhere on campus," as one student put it. The domestic students' reactions to this change seem to be varied and somewhat related to prior intercultural exposure. For instance, students who came to the university with little prior experience of a foreign culture seemed to express an understated sense of being overwhelmed about seeing but not knowing 
TABLE 1.

Categorization of Baseline Data

\begin{tabular}{|c|c|c|}
\hline International & Category & Domestic \\
\hline Individual-based (games, online) & \multirow{4}{*}{$\begin{array}{l}\text { Leisure } \\
\text { Activities }\end{array}$} & Partying Events (holidays, sports) \\
\hline Willing/unwilling to try new activities & & $\begin{array}{l}\text { Fraternity/sorority-based Habits from } \\
\text { high school or prior experience }\end{array}$ \\
\hline $\begin{array}{l}\text { Similar patterns with what they do in } \\
\text { home country }\end{array}$ & & Individual-based (physical exercise) \\
\hline $\begin{array}{l}\text { Group activities (karaoke, dance, } \\
\text { cook, shopping, travel, ethnic event) }\end{array}$ & & Group-based (sports, music, dance) \\
\hline Online SNS & \multirow{8}{*}{$\begin{array}{l}\text { Social Network } \\
\text { Establishment }\end{array}$} & Organization/club-based \\
\hline Class-based & & Through work \\
\hline Hometown-based & & Sports-based \\
\hline Activity-based & & Dorm-based \\
\hline Residence-based & & Class-based \\
\hline Major-based & & Through friends \\
\hline Through friend & & High school friends \\
\hline Organization/club-based & & \\
\hline Prior experience & \multirow{6}{*}{$\begin{array}{l}\text { Drivers for } \\
\text { Intercultural } \\
\text { Interactions } \\
\text { Through Leisure }\end{array}$} & Prior experience \\
\hline Family influence & & Immigrant background \\
\hline Career goal & & Curiosity \\
\hline See the value & & Personality (approachable) \\
\hline Cultural curiosity & & Professional development \\
\hline Personal goal (competence) & & $\begin{array}{l}\text { Prior living environment (big city vs. } \\
\text { no int'l student in high school) }\end{array}$ \\
\hline Group influence & \multirow{13}{*}{$\begin{array}{l}\text { Barriers to } \\
\text { Intercultural } \\
\text { Interactions } \\
\text { Through Leisure }\end{array}$} & Frustration in communication \\
\hline Unwilling to be embarrassed & & Living on-campus, lack of opportunity \\
\hline Reluctant outside comfort zone & & Lack of motives/needs \\
\hline Lack of common grounds/topics & & Lack of common grounds \\
\hline Social norms & & Int'I students like to stay in their own \\
\hline Cultural personality & & 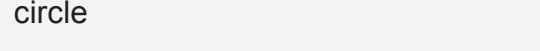 \\
\hline Lack of venues/information & & \multirow{7}{*}{$\begin{array}{l}\text { Language (unwillingness to make } \\
\text { others embarrassed) }\end{array}$} \\
\hline Time constraints & & \\
\hline Homesickness & & \\
\hline Lack of motivation to explore & & \\
\hline Stereotype & & \\
\hline Language & & \\
\hline Whom to tell, whom to trust & & \\
\hline
\end{tabular}


the newcomers. Domestic students who had prior experiences of such interaction tend to take the change as a matter of fact.

Like here just walking around on campus, I see groups of Chinese people speaking Chinese to each other and it is really intimidating ... I I would feel awkward to just walk up to them and talk to them. (Male, domestic, sophomore)

I am from New York. Nothing is really overwhelming to me. I visited countries like China before... When I talk to students from China, I talk to them about city life ... Growing up, my next door neighbor was half Indian, she exposed me to Asian culture. So it is like second nature to me. (Female, domestic, freshman)

The palpable wave of international students was also felt in-group. For instance, Chinese students expressed some degree of surprise to see so many others from their own country on campus.

If I want to only speak Chinese, I will be able to do so. Because I go to Chinese grocery store, socialize on Chinese version (of) Facebook and hang out with Chinese friends. I can even speak Chinese to deal with academic issues. My lab mates are Chinese, too. (Male, international, sophomore)

\section{Theme 2: Activities Take Place in Paralleled Social Networks}

The classroom was indicated as a common venue for both domestic and international students to initiate some social networks. Domestic students established their social circle mainly through fraternities, sororities, residential houses, high school friends, or freshmen orientation programs. International students tended to join international associations on campus to make friends. Online social networks also appeared to play a major role in establishing their social circles, as many of the Chinese students were already connected with each other before leaving China. Upon arrival on campus, these social networks continued to function as major vehicles for them to make friends, participate in sports, and attend social functions.

This year, about one thousand Chinese students got together on our facebook before we came to (the university) . . . If I want to go out dinner with someone, I can always check on our Chinese facebook. (Male, international, freshman)

In general, the Chinese students appeared to be much less engaged or interested in activities designed to introduce campus life to new students.

I went to the (freshmen orientation). Most of us (Chinese) quit after the first day. All Asians disappeared after the first day ... All of them (Americans) were like ha ha ha. What are they laughing about? ... We did not find it interesting. (Female, international, first semester transfer student)

International students reported very limited interactions with domestic students outside the classroom, despite the fact that they participated in similar types of activities such as hanging out with friends and group sports. It appears that in general, Asian students tended to spend leisure time with friends from the same or similar cultural background, causing an alienation from domestic students. When international students did interact with domestic students, the most frequently reported platforms included class projects, dorms, sports, student organizations, and hobby-based clubs. It was a common sentiment of international students that interactions with domestic students were limited, brief, and unsustainable, sometimes resulting in discouragement and departure.

I cook and eat with my Chinese friends. Going shopping sometimes too. I do not hang out with foreign (domestic) 
people. But in group projects-yes. (Male, international, junior)

I lived with two Americans (on campus). At first, we get along well. We always go to the gym together. But as time goes by, they have their own life. They go to fraternities and I go to my organization (Chinese student organization). So we grew apart. (Male, international, junior)

A small percentage of domestic students with outgoing personalities were involved in many kinds of activities with both international and domestic students. The majority of domestic students, however, indicated that they had had very limited-to-no interaction with international students outside the classroom. The interactions tended to be unsustainable, similar to the sentiment of international students. "Have not done anything with them" was a common expression. Among those who were somewhat connected, however, both domestic and international students indicated that their interactions stayed at a very basic and superficial level, such as exchanging pleasantries. After that, topics quickly dried up and interactions became toiling and as a result tended to cease.

I tried to say hi. And all I will get was hi back. I don't really know how to start conversation. So it is like "How are you?" and then "good." I don't know if she just didn't know or she is shy or what. (Female, domestic, sophomore)

\section{Theme 3: Willingness Is Abundant but Few Make Meaningful Intercultural Contacts}

Another common theme noted is that both domestic and international students expressed interest and willingness to interact more with each other, although there was more in-group variability among the domestic students than among the international students. The majority of international students expressed a strong desire to know the "local/domestic people," as many students put it. Almost all indicated that they had the intention to immerse themselves in American culture before arrival. Many international students expressed disappointment and dissatisfaction when it came to interacting with American students. The domestic students expressed similar willingness about interacting with international students more, although some never thought about doing so until the topic was discussed. In general, out-of-state students and transfer students seemed to be more enthusiastic about such ideas.

Why do I come to America to study? I have been here for two years. I have always hung out with Chinese and other international students. But I came to America to study and I thought I should have more contact with local people here and learn about their culture. I am sometimes mad at myself for not trying harder. (Female, international, junior)

Although both groups appeared to view more interactions positively, the reality is that extensive and in-depth conversations rarely took place, and interactions at activities were even fewer. Some students indicated that they were hesitant because they were unsure about how to start and sustain a dialog. There also appeared to be misunderstandings and misinterpretations of each other when it came to whether the other party cares to talk to them.

I would talk to them. I have done study abroad in China. But they do not care about talking to me. I live in (student dorm). There are so many Chinese there. They don't want to talk to me. They never talk to me! (Female, domestic, senior)

It's a stereotype thing. People are not willing to take effort to know you. (Male, international, sophomore) 


\section{Theme 4: Language Is a Barrier but Cultural Barricade Is Bigger}

Students indicated that their ability to comfortably and effectively interact with someone from a foreign culture was very limited. The sentiment was shared by both domestic and international groups. During the focus group sessions, they openly and willingly shared their perspectives of what inhibited them from engaging in intercultural interactions. One shared view was that language was a major barrier for intergroup communication. For the domestic students, the foreignness of international students' cultural protocols and accents deterred them the most. For international students whose native language is not English, speaking English outside the classroom was a major challenge, especially on topics not directly related to course content.

Mostly language ... I would say things differently from what they would say ... They say things backwards ... I feel like I am being rude. I may have made them feel stupid-just this one big mess — might as well just give up. (Female, domestic, junior)

When we hear local people talk to each other, it is very difficult ... They use many phrases we are not familiar with and it is not in the textbook. (Male, international, sophomore)

The lack of understanding of cultural and behavioral norms and social protocols appeared to be an even more daunting hurdle for the international students, although this inhibiting factor could be somewhat related to language skill deficiency. Students hesitated to reach out to the other group to learn about each other's cultural and social customs. Feelings of awkwardness, selfconsciousness, overwhelm, and embarrassment were frequently mentioned.
If the Americans don't talk to us first, we don't know how to talk to them. We don't know the rules. When I tried, I say the weather is good and he says yeah the weather is good. (After that), we don't know how to talk. (Male, international, sophomore)

Every place has different culture. What is respectable, what is not respectable. Like Asians are a little bit more respectable to like older people. So I was always wondering if they even think of us as being rude. (Female, domestic, junior)

Some international students appeared to believe that different cultural personality characteristics and values may have prevented them from having meaningful interactions.

Americans are focused on free style ... do what you want ... just do it and don't care about what other people say. In our culture, you can't say the truth directly it will hurt people ... Be humble. Hide yourself. That makes a huge obstacle. (Male, international, sophomore)

Another shared sentiment related to cultural difference was the lack of common ground, a result of the different cultural contexts in which they were brought up. Participants frequently pointed out that these background differences resulted in a lack of common ground and topics for interaction. Consequently, when it came to having a casual and social conversation, different popular culture, social expectations, and life experiences tended to set the two groups apart. Participants also noted the difficulties of pronouncing and remembering foreignsounding names, as well as recognizing faces due to unfamiliarity with a different culture. Such difficulties were said to have further exacerbated the communication-related issues.

For me, it is the names. They are so different . . . I am not going to remember your name the first few seconds. It would 
be so much easier to talk to you again (if I know your name). I feel really bad. It is like hey you! (Female, domestic, junior)

\section{Theme 5: We Live in Structurally Different Communities}

In spite of the multicultural presence in the neighborhood, students felt that they lived in separate communities. That feeling was particularly strong for the international students. The campus size and cultural diversity may actually have a negative impact on intercultural interactions. Some students noted that the presence of the large international community provided a certain cultural safety net in which students are likely to become more cohesive within their own community while becoming alienated from other groups.

I think the size of the campus and the diversity of the school actually has a negative impact on interaction. When there are so many ... different kinds of people, you just feel like you just want to be with people who are like you. (Male, domestic, junior)

Before we came here, everyone wanted to get to know American people but after we came here, there are so many of us. You can't avoid talking to Chinese. We don't get around to talk to Americans. When there is a large group of us-a large (Chinese) community, you tend to stay within the community. (Male, international, senior)

\section{Theme 6: Interact or Not: What Is in It for Me?}

Both domestic and international students agreed that cultural interactions are useful. However, it appeared to matter somewhat differently for the two groups. Domestic students associated intercultural exchange with long-term benefits, whereas international students appeared to relate such opportunities to fulfilling more immediate or short-term needs. Domestic students saw the value of intercultural interactions as a means of personal and professional development. Some repeatedly emerging themes that students addressed include "broaden horizon," "grow character," "exposed to more opportunities," and "be successful with the major/future job."

You can feel that people have their own value. You say some things differently. They might even get upset and say no, you are wrong. It is this way. If you are exposed to a lot of different cultures, you understand that everybody thinks differently. Everybody has their values. Nobody is right and nobody is wrong. (Male, domestic, sophomore)

International students acknowledged the values of language learning, making more friends, and better immersing themselves in local cultures. It is noteworthy that they tended to associate interactional opportunities with the educational or even overall quality of their US experience. The lack of it led to sentiments of surprise, disappointment, and frustration.

I feel that I am in Korea sometimes. I really want to have more connections with domestic people. That's one of the reason I want to study here. I could have studied in my country. My initial plan was to not interact with Korean people but I couldn't do it because I was really lonely. I lived off campus. (Female, international, freshman)

\section{Theme 7: Opportunities, More Advocated Opportunities}

Both groups concurred that the reality of intercultural interaction was less than satisfactory. They agreed that there should be more interaction, with better awareness and education and more structured support by the university and the community. The existing student clubs and organizations were in some cases perceived as not integrated and diverse when it came to their cultural composition. 
They have all kinds of stuff around campus and community. We have always things like fair, theater, or just like free concert ... But not everyone necessarily does it. They would like to go with their group of friends. (Female, domestic, sophomore)

I am a transfer student. My old school-I just join their international club. I would say half of them are Americans. But here I join the same club. All of them are international students. Many of them (are) Asian. (Female, international, junior)

When asked to suggest interactional opportunities on campus, participants identified a series of venues including classes, clubs, student organizations, the learning community, football games, and events organized by residential houses. Personal initiatives and motivations were found to be important in exploring existing opportunities. They believed that a willingness to embrace differences, such as patience with English-language limitation, would lead to the discovery of bright ideas.

As first-generation American, I felt some connections or chemistry/sparks with international students. They open up really fast. Although their language is not up to par, we always have meaningful conversations. (Male, domestic, junior)

Many participants indicated that personal effort played an important role in the intercultural exchange process, as students need to venture beyond their comfort zone in such situations. When there is limited or no incentive for such effort, people tend to stay in their comfort zone.

It is easier to talk to people coming from the same culture. The interaction (with other cultures) is pretty intense, not a relaxing experience. (Female, domestic, freshman)

Many students addressed the lack of venues outside the classroom to get to know students from other cultures. Some suggested the addition of a more formal structure to facilitate intercultural interactions on campus. For instance, students recommended that extra-credit activities or classes be arranged to promote a one-on-one or deeper level of interaction between domestic and international students, such as spending one day getting to know each other. "If the university gives us credit for playing tennis, why not this?", as one domestic student put it. More culturally inclusive student organizations/ clubs and culturally oriented activities (such as ethnic cooking) were also suggested as potential platforms for comfortable and fruitful exchange experience.

\section{Theme 8: Direct, Face-to-Face Dialogue, Please}

The opportunities for students to directly discuss intercultural issues are valuable, as evidenced during the focus group sessions in the current study. Although the participants reported only sporadic interactions among the culturally different groups, a very positive attitude and enthusiasm toward having better opportunities to interact interculturally were apparent during each of the nine sessions. Students were going through an evolving, clearly delineated process of (a) recognizing the different cultural presence, (b) interacting with each other, (c) giving meaning to such interaction (internalizing), and (d) settling into a state of ease in talking and discussing with and among each other. The sessions always started with uneasiness toward each other. Toward the end, the two groups were much more relaxed about each other, feeling more comfortable, and even joking with each other about the misuse of words or innocent mishaps as a result of not knowing what to do in an intercultural setting. The participants felt the focus sessions brought students together effectively, however brief such effects may be. A common sentiment from the participants is that given heightened intercultural awareness 
and a facilitated platform to act on it, students from different cultural backgrounds can start a meaningful dialogue.

\section{DISCUSSION AND IMPLICATIONS}

\section{Effect of Simultaneous Multicultural Representations}

Globalization has brought diverse cultures together in an unprecedented way, with simultaneous multicultural representations manifesting themselves in many settings. The US college campus is one such setting due to the large infusion of international students. The large co-presence of students from very different cultures encourages them to cocoon in their own cultural-based communities rather than branching out and interacting with students of other cultures. When interactional experiences are too exerting or not relaxing, students quickly revert back to their own comfort zone. This in-group clustering phenomenon seems to be more prominent for the Chinese students than for other international students who are less prominently represented on campus due to their smaller enrollment numbers.

This finding is consistent with the social cognitive proposition by Chiu and Cheng (2007) that activating two cultural representations "enlarges the felt distinctions between different identity options and hence magnifies the effects of identity choice" (p. 14). However, such multicultural diversity, when harnessed appropriately, can foster creative problem solving and allow creative conceptual expansion (Chiu \& Cheng, 2007). It is therefore imperative for US universities to manage and, more importantly, to strategically channel such diversity into synergistic and positive assets. As Hammer (2008) pointed out, culturally diverse resources should be fully integrated into the life of an organization so that they are valued and activated, leading to optimal performances. If left unmitigated, they can reinforce stereotyping and discord.

\section{Aversive Racism Effect}

The cultural-based in-group clustering phenomenon and feelings of uneasiness toward students from a different culture may also be understood in light of the aversive racism framework (Dovidio \& Gaertner, 2004). Aversive racism refers to a subtle form of bias due to differences in cultural practices and normal cognitive bias. One proposition suggests that bias may be represented more in the form of pro in-group sentiment than anti out-group bias (Gaertner \& Dovidio, 2000). It was noted in this research that students prefer cultural groups to which they belong over groups to which they do not. When students identify themselves strongly along cultural or national identity lines, they tend to subconsciously avoid stepping beyond the cultural boundary. The inexplicit aversiveness of intercultural groups was apparent from this research.

Aversive racism also suggests that bias is not outwardly expressed in terms of hostility, but rather shown in the form of discomfort, uneasiness, and sometimes fear (Gaertner $\&$ Dovidio, 1986). It was noted that when domestic and international student groups do interact, most voiced some level of anxiety and uncertainty, sentiments that tend to motivate avoidance. This may explain why it seems that although desires to interact interculturally are apparent for both domestic and international students, their willingness to exert energy to challenge language and cultural boundaries is fairly limited. Both groups are comfortable living in their own communities or returning to their comfort zone as soon as their interactional experiences become challenging. 
Effect of Intercultural Interactional Skill: The Lack of It

Interactional skills in the intercultural context are of great importance, as the ability to effectively interact and work across cultures is perceived as one of the core competencies for all undergraduate students (Lohmann, Rollins, \& Hoey, 2006). The study findings indicate that there is an effect of intercultural interactional skill—or rather the lack of it - that underlines why domestic and international students seem to live in parallel communities. Intercultural communication competence is a function of two parties' motivation to communicate, their knowledge of communication in that context, and their skills in carrying out the interactional tasks (Spitzberg, 2000). Both domestic and international students have intergroup interaction motivations, albeit to a varying degree. It is apparent from this research, however, that both groups find it challenging to actually interact comfortably with each other, especially in a less structured setting outside the classroom. While the students saw why such intercultural exchange can be useful, they did not seem to possess the practical know-how. Knowledge of the importance of such exchanges alone does not enable students to participate in them. The association of the two is not necessarily high unless students feel they have the skills to do so. That did not seem to be the case with the focus group participants. Students who had had opportunities to interact interculturally outside the classroom found the experiences less fulfilling than anticipated. They perceived both themselves and the other party as communicatively incompetent. This indicates that most students do not possess sufficient interactional skills to comfortably engage in intercultural interactions.

In the case of the Chinese students, the situation is almost paradoxical. They made it clear that they came to the United States fully intending to learn about its culture and people. They were dissatisfied and sometimes frustrated with the lack of meaningful interactions with American students and the local community at large. On the other hand, they seemed to exhibit a tendency to interact almost exclusively with fellow Chinese students and live entirely in their own cultural community. This isolation can be a concern and may potentially lead to negative perceptions of overall educational experience and dissatisfaction, and of each other. To some extent, this paradox can be explained by a combination of the three effects discussed above.

\section{Practical Implications: Developing Interactive Skills Interculturally}

The multinational campus dynamics present on US campuses can provide a unique opportunity for cultivating multicultural competency. The study findings suggest that the mere presence of multicultural groups on campus does not automatically result in intercultural interactions, which are a prerequisite to the development of multicultural competency. In fact, there is evidence that as the number of students from one specific country increases, so does the size of their comfort zone, making them less likely to interact with others. This and other findings highlight the challenges for US campuses to better utilize the rich multicultural resources in developing students' multicultural competency and readiness to be successful in a global environment. A number of practical implications can be drawn from the aforementioned findings and analyses.

First, systematic interventions must take place to make international students become an integral part of the student body. Traditional orientations and welcome picnics at the beginning of their first semester are not sufficient anymore. Without persistent and ongoing interventions, the international 
students may retreat back to their own "communities" fairly quickly. As suggested by Gaertner and Dovidio (2000), interventions may be aimed at building common identity. For instance, although the role of intercollegiate athletics is multidimensional and even controversial sometimes, few would disagree that college sports such as football rally the campus constituents past and present. They forge emotional ties of students and alumni to the university, but such connection to a common identity only happens when the students participate in the sports as spectators or in other roles. College football is uniquely American. While domestic students take the tradition for granted, it is foreign to international students. Without purposefully including them, the university may have effectively pulled the welcome mat out from under their feet upon their arrival when the beginning of their freshman year coincides with the start of the college football season.

Second, if the university is the new home of the international students, the community where the university is situated is their new hometown. As part of their adaptation to the new home and hometown, organized visits to the institutions of adjacent towns and counties can familiarize the international students with prevalent social norms and cultural practices of their new neighborhoods. One of the study's findings is that the students' self-perceived level of intercultural skills is low, resulting in a sense of discomfort and anxiety in interactional scenarios. Just as going to college sports events can help international students to be integrated into the campus life, these community visits can be a means of integrating them into the life of the larger society. Both need interventions by the university administration, because the majority of international students, strangers to their new home and new hometown, are unlikely to take these nonacademic initiatives on their own.
Third, while integration of the international students into campus and community life is a means to foster a sense of common identity, the process of it could enable both international and domestic students to accumulate knowledge and gather confidence in initiating interactions with domestic students. By no means, however, should the efforts spent on international students be interpreted as an unreasonable burden on the university, nor the attempts be regarded as placing the "burden" of reaching out onto the international students. Rather, these efforts and attempts are worthy investments to develop the international students as cultural resources that benefit both themselves and their domestic peers. Appreciation of diverse cultures and utilization of multicultural resources on multinational campuses must be built on a common identity. Otherwise, the campus looks and feels like a bowl of untossed spring mix salad without flavoring or dressing.

Fourth, this research shows that students are aware of their campus's multicultural composition and understand that, once they graduate, they are likely to work with people from different cultures; performing well in a globalized economy will therefore require them to have competency in intercultural skills. However, if differences in culture are perceived as a liability or as only a one-sided act of kindness, such as emphasis on the appreciation of other cultures, the students will not be stimulated enough to pursue intercultural interactions. The university administrators, faculty, and staff should bring the message to the students that the presence of different cultures is a precious asset and that they are committed to making the asset available. For example, a credit-based outdoor interactive activity between domestic and international students may be more effective in developing multicultural competencies than a lecturebased in-class course on textbook knowledge 
of a culture. Recruiting international students as guides of study-abroad trips to their home countries could be another such initiative. Further, an honors program or course may follow an unconventional format that will integrate in-class activities such as debates on intercultural issues with outside-the-classroom events that require intercultural collaborations.

\section{CONCLUSION}

This study provides a picture of the interactional experiences and perceptions outside the classroom among domestic and international undergraduate students on a US campus. The findings illuminate the lack of and challenges to integration. The presence of a large number of international students evokes the activation of culture effect in both international and domestic students. The psychological impact of being exposed to foreign cultures may vary from exclusionary nationalist sentiments to inspiring novel idea generation. Effectively harnessing and capitalizing on such cultural diversity bears strategic implications, ranging from global competency development to the linkages between intercultural interactions and overall student satisfaction with their educational experience. If universities can implement mechanisms that facilitate meaning- ful intergroup contact and interactions among the different cultural groups on campus, they will essentially establish an efficient means for cultivating multicultural and global competence. For example, a class with a focus group-like structure may work as a bridging platform for sensitizing students' intercultural awareness and encouraging and facilitating interactions. Systematic and specific measures should be developed with leadership commitment and campus-wide deliberations.

The data for this study were gathered from a major land-grant university in the midwestern United States. The intercultural dynamics of the campus at issue, however, are fairly representative of most large universities in the United States. The findings should bring attention to the challenges and opportunities multinational campuses in the United States currently face. As such, the research makes a significant and timely contribution to building a campus with cultural richness and diversity and developing students' readiness to be successful in a global environment.

Correspondence concerning this article should be addressed to Xinran Y. Lehto, Marriott Hall, Room 257, 900 W. State Street, West Lafayette, IN 47907; xinran@purdue.edu 


\section{REFERENCES}

Allport, G. W. (1954). The nature of prejudice. Cambridge, MA: Addison-Wesley.

Barron, P., \& Dasli, M. (2010). Towards an understanding of integration amongst hospitality and tourism students using Bennett's developmental model of intercultural sensitivity. Journal of Hospitality, Leisure, Sport and Tourism Education, 9(2), 77-88.

Braun, V., \& Clarke, V. (2006). Using thematic analysis in psychology, Qualitative Research in Psychology, 3, 77-101.

Brown, R., \& Hewstone, M. (2005). An integrative theory of intergroup contact. Advances in Experimental Social Psychology, 37, 255-343.

Brown, B. B., \& Klute, C. (2006). Friendships, cliques, and crowds. In G. R. Adams \& M. D. Berzonsky (Eds.), Blackwell handbook of adolescence (pp. 330-348). Oxford, England: Blackwell.

Burch Jr., W. R. (2009). The social circles of leisure: Competing explanations. Journal of Leisure Research, 41(3), 313-335.

Carlsen, B., \& Glenton, C. (2011). What about N? A methodological study of sample-size reporting in focus group studies. BMC Medical Research Methodology, 11(1), 26-35.

Chiu, C.-Y., \& Cheng, S. Y.-Y. (2007). Toward a social psychology of culture and globalization: Some social cognitive consequences of activating two cultures simultaneously. Social and Personality Psychology Compass, 1, 84-100.

Creswell, J. W. (1998). Qualitative inquiry and research design: Choosing among five traditions. London, England: SAGE.

Creswell, J. W. (2007). Qualitative inquiry and research design: Choosing among five approaches (2nd ed.). Thousand Oaks, CA: SAGE.

Deardorff, D. K. (2006) Identification and assessment of intercultural competence as a student outcome of internationalization. Journal of Studies in International Education, 10(3), 241-266.

Dovidio, J. F., \& Gaertner, S. L. (2004). Aversive racism. In M. P. Zanna (Ed.), Advances in experimental social psychology (Vol. 36, pp. 1-52). San Diego, CA: Academic Press.

Floyd, M. F., Shinew, K. J., McGuire, F. A., \& Noe, F. P. (1994). Race, class, and leisure activity preferences: Marginality and ethnicity revisited. Journal of Leisure Research, 26, 158-173.

Gaertner, S. L., \& Dovidio, J. F. (1986). The aversive form of racism. In J. F. Dovidio \& S. L. Gaertner (Eds.), Prejudice, discrimination, and racism (pp. 61-89). Orlando, FL: Academic Press.

Gaertner, S. L., \& Dovidio, J. F. (2000). Reducing intergroup bias: The Common Ingroup Identity Model. Philadelphia, PA: Psychology Press.

Hammer, M. R. (2008). The Intercultural Development Inventory (IDI): An approach for assessing and building intercultural competence. In M. A. Moodian (Ed.), Contemporary leadership and intercultural competence: Understanding and utilizing cultural diversity to build successful organizations (pp. 219-232). Thousand Oaks, CA: SAGE.

Institute of International Education. (2011). Open Doors 2011: International Student Enrollment Increased by 5 Percent in 2010/11. Retrieved from http://www.iie.org /Who-We-Are/News-and-Events/Press-Center/Press-Releases /2011/2011-11-14-Open-Doors-International-Students
Kaase, K., \& Harshbarger, D. B. (1993). Applying focus groups in student affairs assessment. NASPA Journal, 30(4), 284-289.

Kelly, B. T. (2003). Focus group interviews. In F. K. Stage \& K. Manning (Eds.), Research in the college context: Approaches and methods (pp. 49-62). New York: Brunner Routledge.

Lohmann, J. R., Rollins, H. A., \& Hoey, J. J. (2006). Defining, developing and assessing global competence in engineers. European Journal of Engineering Education, 31(1), 119-131.

Morgan, D. L. (1996). Focus groups. Annual Review of Sociology, 22, 129-152.

Paul, B., \& Lynne, M. (2001). Organizational research methods: A guide for students and researchers. London, England: SAGE.

Pavel, S. (2006). Interaction between international and American college students: An exploratory study. Wesleyan Journal of Psychology, 1, 39-55.

Pettigrew, T. F. (2008). Future directions for intergroup contact research. International Journal of Intercultural Relations, 32, 187-199.

Rockenbach, A. B., Walker, C. R., \& Luzader, J. (2012). A phenomenological analysis of college students' spiritual struggles. Journal of College Student Development, 53(1), 55-75.

Russell, M. (2005). Marketing education: A review of service quality perceptions among international students. International Journal of Contemporary Hospitality Management, 17, 65-77.

Sherry, M., Thomas, P., \& Chui, W. H. (2010). International students: A vulnerable student population. Higher Education: The International Journal of Higher Education and Educational Planning, 60(1), 33-46.

Spitzberg, B. H. (2000). A model of intercultural communication competence. In L. A. Samovar \& R. E. Porter (Eds.), Intercultural communication: A reader (9th ed., pp. 375-387). Belmont, CA: Wadsworth.

Sumer, S., Poyrazli, S., \& Grahame, K. (2008). Predictors of depression and anxiety among international students. Journal of Counseling and Development, 86(4), 429-437.

Trice, A. G. (2004). Mixing it up: International graduate students' social interactions with American students. Journal of College Student Development, 45(6), 671-687.

Turner, Y. (2006). Chinese students in a UK business school: Hearing the student voice in reflective teaching and learning practice. Higher Education Quarterly, 60, 27-51.

Vaughn, S., Schumm, J., \& Sinagub, J. (1996). Focus group interviews in education and psychology. Thousand Oaks, CA: SAGE.

Zajonc, R. B. (1968). Attitudinal effects of mere exposure. Journal of Personality and Social Psychology, 9, 1-27.

Zimmerman, S. (1995). Perceptions of intercultural communication competence and international student adaptation to an American campus. Communication Education, 44, 321-333. 